Fourth International Conference on Sustainable Construction Materials and Technologies http://www.claisse.info/Proceedings.htm

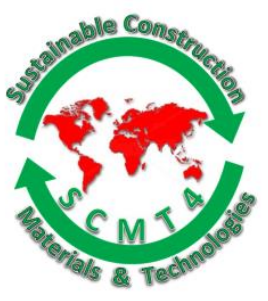

SCMT4

Las Vegas, USA, August 7-11, 2016

\title{
Development of Rapid PCC Pavement Repair Materials
}

\author{
Denita Walker ${ }^{1 a}$, and Alex Hak-Chul Shin ${ }^{1 b}$ \\ ${ }^{1}$ Department of Civil and Environmental Engineering, Southern University and A\&M College, Baton \\ Rouge, Louisiana 70813

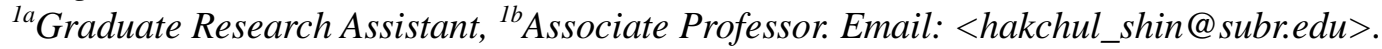

\begin{abstract}
Being that pavement repair and construction represents a significant percentage of federal and state funding, new techniques are being investigated to reduce cost and generate a more resilient material. The goal of the project is to develop cost-effective, high performance concrete materials for rapid road repair. In addition, reducing environmental impact and the level of effort are of concern. Therefore, experimental study was conducted to investigate sustainable concrete with recycled concrete aggregate (RCA), lightweight aggregate (LWA), and other materials to improve the strength during the period of this project. The focus of this research is to study sustainable materials (RCA) as it relates to the development of fulldepth repair materials and techniques through a series of trial mixes. Crack-free early strength concrete using internal curing for light-weight aggregate and recycled concrete full-depth pavement repair will begin the study and the components in which are considered to minimize stresses and shrinkage at early-ages. In this research, relations between sustainable test materials and high compressive strength 4000 psi was recorded after 4 hours. The mix designs was adjusted base of the data. Through more comprehensive tests trials will be carried out to suggest an optimum mix proportioning for sustainable high-early strength concrete.
\end{abstract}

\section{INTRODUCTION}

Southern University is a consortium of University Research Center (UTC), RE-CAST (REsearch on Concrete Applications for Sustainable Transportation) in conjunction with the following universities: Missouri University of Science and Technology, Rutgers University, Southern University, University of Illinois at Urbana-Champaign and University of Miami. The focus is to introduce the next generation of cement-based sustainable construction materials resulting in the implementation of the technologies being researched and the improvement of current guidelines for the purpose of infrastructure rehabilitations.

There are many civil infrastructures all over the country that have brought awareness that cementious materials must be improved in terms of property and durability in rapid pavement repair. However, it is not rare that another repair is required shorty after because of early, severe cracks in pavement repair due to dry shrinkage. Adaptive rheology concrete and crack-free high-earl-strength concrete containing sustainable materials are investigated to resolve this issue in pavement repair. A solution suggested in this project, is to use a variety of sustainable materials including shrinkage reducing admixture, expanded shale, light weight aggregate, superabsorbent polymer, fiber, and recycled concrete aggregate (RCA) as replacement 
of virgin aggregate partially and is expected to minimize the construction length and enhance long term performance, resulting in reducing indirect and direct cost.

High early strength concrete in rapid pavement repair is necessary due to the opening requirement of pavement to traffic hours after replacing repair concrete. Rapid patches are methods that are currently being practice today and in most cases show signs of repair shortly after placement. Loose or crumbling concrete and moderate, shatter-like cracking are sign of design issues or insufficient material which causes frequent pavement patch repairs. Thus, there being a demand for crack resistant repair materials that have extended, more durable concrete patches which includes the use of shrinkage reducing methods, fibers, recycled materials, and internal curing.

Internal curing (IC) is a practical way of supplying additional curing water throughout the concrete mixture. ACI (2010) defined internal curing as "supplying additional curing water throughout a freshly place cement mixture using reservoirs, via pre-wetted lightweight aggregates, that readily release water as needed for hydration or to replace moisture lost through evaporation or self- desiccation $[\mathrm{ACI}]$." The following are the benefits of IC:

- Increase in strength

- Coefficient of expansion reduction

- Reduction of shrinkage

- Decrease in elastic modulus

The absorption of water of aggregates in aggregates not only increases strength, but reduces early shrinkage in concretes with low water to cementitious materials contents $(\mathrm{w} / \mathrm{cm})$.

\section{Recycled Concrete Aggregate (RCA)}

Since using natural resources and disposing of construction and demolition wastes in large quantities are no longer considered sustainable because of environmental and economic implications, government policies are being directed towards reducing the use of these resources and increasing reuse and recycling [Lauritzen, 1998, Hansen 1992]. Therefore, recycling of construction/demolition waste as aggregate in new concrete pavement gives an environmentally responsible and economically feasible alternative to use the material as a valuable resource [Limbachiya 1998, Dhir et al. 1999, and Limbachiya 1998]. RCA is created by demolishing or crushing concrete that is at the end of its service life. Depending on its intended application, concrete as a construction material exhibits a wide range in physical and mechanical properties. As a result of this, RCA shows inconsistencies in terms of physical properties which may make it not as desirable for usage as coarse aggregate in new concrete pavements.

The sustainability of RCA for the use in normal grade concretes meeting requirements for various applications, namely foundations, paving, reinforced and pre-stressed concrete, has been examined by the authors and reported elsewhere [Kikuchi 1993]. In this, methods were established for taking account of inherent RCA characteristics in the production of concrete that is stable in the fresh state and able to develop properties comparable to corresponding natural aggregate concrete in the hardened state. Furthermore, the work suggested that the use of coarse RCA may be extended to high-strength concrete, thus offering further added value outlets for the material.

The use of RCA in high-strength concrete has been examined in relatively few studies and experimental data are limited. A study considering high-strength concrete containing coarse RCA contents of 5, 10, and $12.5 \%$ indicated that the strength at a given water/cement (w/c) ratio was similar to that containing natural aggregates [Rvindrajah 1988]. Similar results have been reported by other researchers [Zhutovsky et al, 2001]. Whilst these studies suggest potential for RCA use in high-strength concrete, issues relating to durability or long-term performance, relevant to practice, have never been considered. 
For this project, we propose internal curing for recycled concrete aggregates for high early strength concrete providing internal curing at an early age. High early strength concrete has low $(\mathrm{w} / \mathrm{cm})$ which produces self-desiccating shrinkage at early age and is inclined to early age cracking and corrosion. Thus making it necessary to provide the moisture inside the concrete to prevent shrinkage and deterioration. With a higher absorption capacity this may show the potential of RCA to provide some internal curing benefits when it is casted in concrete. As noted that internal curing is a process of entraining water in the reservoirs inside the concrete so that it is drawn from those reservoirs resulting as beneficial to the cement hydration process.

\section{Saturated Lightweight Aggregate Replacement}

Studies reported in recent years suggested that the amount of water within the aggregates which was required for the elimination of self-desiccation and autogenous shrinkage was considerably high. The explanation for this apparent discrepancy is that not all the water in the aggregates can become effective to counteract self-desiccation. Several factors can be considered, such ads: (i) Aggregate into the surrounding paste, and (ii) The spacing between the aggregate particles: if it is too large the paste surrounding the aggregates may not be accessible to the water in the aggregate within a reasonable time (this limitation can be quantified in terms of the diffusivity of the water into the surrounding matrix which becomes denser with time). These influences may be expressed in a simplified engineering approach in terms of an efficiency term, $\mathrm{n}$, which is a factor in the range of 0 to 1 , describing the portion of water in the aggregate which can become available for internal curing. This factor is the result of complex function and is not only dependent on the properties of the aggregate [Bentur et al.].

Ideally, one would like to develop aggregates for internal curing where the efficiency factor, $\mathrm{n}$, is 1 , the water absorption is as high as possible, to minimize the aggregate content required to obtain effective internal. To achieve this, one would resort to aggregates of a small size and a pore structure which is large and coarse. Small size of particles would minimize the distance between the reservoirs, making the paste volume to be more accessible to the water in the internal reservoirs. Coarse pore structure of the aggregate is beneficial to make the water more readily dischargeable into the surrounding paste. A large pore volume in the aggregate may have two opposing influences: it may enable to minimize the LWA content, but at the same time it will increase the spacing between the aggregate. Thus, from the point of view of the effectiveness of the aggregate, there may be an optimal pore volume for a given aggregate size [Bentur et al.].

\section{Type III Cement}

The higher fineness of Type III cement provides for an increase in the hydration process due to the greater surface area. This increase in surface area may also lead to a higher water demand for the concrete mix, as well as increased long term drying shrinkage. Higher concrete temperatures and earlier initial set times are common and should be accounted for in the job. The materials engineer and contractor should be aware of these phenomena when testing mixtures and trail batches. Tests should be conducted using the same cement that the contractor will use in construction. [ACI 325.9R]

A sufficiently low water-cementitious materials ratio is critical to achieving the strength and durability needed for concrete pavements [Taylor et al. 2007]. Generally, a w/cm between 0.40 and 0.50 provides moderate chloride permeability for concrete made from conventional materials. A w/cm below 0.40 typically provides low chloride permeability, though the use of certain supplementary cementitious materials may be a more important strategy for achieving very low chloride ion permeability [Whiting 1981]. Some accelerated-paving mixtures have a ratio less than 0.43 and, consequently, provide moderate to low permeability. 
It is important to remember that durability is not a function of early strength but is a function of long-term strength, w/cm, permeability, a proper air void system, and aggregate quality. Mixtures using these materials may appear to meet the quick strength development necessary for accelerated-concrete paving but may not provide adequate durability. Because of this inconsistency, a mixture should be evaluated at various ages to ensure it meets both early strength and long-term durability requirements.

Type III cement is designed to develop early strength quicker than a Type I, II cement. This is beneficial for promoting a rapid pace of construction for road repair, since it the concrete can tolerate loads sooner. The downsides of Type III cements are, there is a small window frame of workability, greater heat of hydration, and a somewhat lower final strength. In addition, while mixing, it was necessary to add material in the same order for each mix otherwise it may have led to inconsistencies. After concrete is mix, casting begins promptly. Casting involves rodding, vibrating, and then placing them in an ice cooler.

\section{Set Accelerator}

Accelerating admixtures aid strength development and reduce initial setting times. Accelerating admixtures generally consist of soluble inorganic salts or soluble organic compounds and should meet requirements of ASTM C494, Type C or Type E. Calcium chloride is the most common accelerator used in concrete. However, this accelerator can promote corrosion of embedded steel and can also lead to other concrete durability issues; as a result, sometimes non-chloride accelerators (such as calcium nitrate) are used.

Many agencies use calcium chloride in their concrete mixtures for full-depth and partial-depth concrete pavement when 6- to 8-hour EOT (Early-Opening-to-Traffic) is required. It is very important to test both fresh and hardened concrete properties before specifying a mixture containing an accelerating admixture.

In general, an accelerator will likely be required for the 6- to 8-hour EOT concrete mixture. For the slower hydrating 20- to 24-hour EOT concrete mixtures, accelerators are not required. It is therefore recommended that judicious use of accelerators be made in accordance with manufactures' recommendations to achieve required early strength [Van Dam et al. 2005].

Adding admixtures may help concrete mixture designers achieve desired concrete properties more efficiently or economically than adjusting other ingredients or mixture proportions. To avoid incompatibility issues, by use of multiple admixtures in one mixture, admixtures were purchased from the same manufacture.

\section{Silica Fumes}

Silica fumes is a common SCM. They can be blended at a cement plant to produce ASTM C595/C595M blended cements or added separately at the concrete plant. Silica is used for high-performance concrete applications, is not normally used in paving because of loss of workability and cost [Taylor et al. 2007]. It has been suggested that only fly ash and slag cement be used in paving applications [Tayabji et al. 2012], although natural pozzolans have been used. Silica fume must conform to ASTM C1240 and the optional testing for reactivity with cement alkalis must also be completed. It is typical to use silica in a range of 6 to 10 percent a suggested amount is required. There are many benefits of SCM replacements of Portland cement during construction are improved workability, and lower water demand. Subsequent benefits to construction include increased long-term strength, reduced permeability, and increased resistance to sulfate attack. 


\section{EXPERIMENT}

A meeting was set up with the LA DOTD (Louisiana Department of Transportation and Development) office in Port Allen to discuss the procedure of full depth repair and the mix proportions used for the concrete they are currently using. The engineer on site used a high early strength concrete with a projected compressive strength of 4000 psi in 4 hours. RCA was not included for the high-early strength concrete by the DOTD. However, high-early strength has a drying shrinkage issue in many cases. Therefore, highearly strength concrete with recycled aggregate is being develop at SUBR to improve service life of highearly strength concrete. For this purpose, experimental tests were carried out to investigate the internal curing effect of RCA on concrete compressive strength and thus to find optimum mix proportioning for sustainable high-early strength concrete pavement. Main material properties such as specific gravity (SG) and absorption capacity (AC) were measured for each batch. The mix proportions for the first batch included coarse recycled aggregate, fine aggregate (sand), water, and cement to have a compressive strength of $4 \mathrm{ksi}$ at 28 days. The process of internal curing was not used on the first batch so that its strengths could be compared with future batches that would use the process of internal curing. The second mixture was casted using pre-wet RCA. The third batch of concrete was casted. For this batch, not only coarse RCA but also fine RCA was used instead of ordinary sand. A No. 4 sieve was used to separate the coarse and fine RCAs. The fourth batch of concrete was casted following the mix proportions provided by the DOTD. The mix proportioning of the 4th batch was for high-early strength concrete and the compressive strengths of the 4 th batch were much higher than the rest as expected. The rest of the specimens indicated similar strengths which were close to the aimed value of $4 \mathrm{ksi}$ at 28 days. In addition, an evaporation test was performed on the recycled aggregate to see how long it took for the internal moisture to completely evaporate. The water inside the RCA quickly evaporated for the first day and then the evaporation rate decreased. It took eight days for internal moisture and water in the RCA to completely evaporate.

Before mixing the specific gravity of RCA and LWA needed to be determined to calculate absorption capacity which is defined as:

$A C=\left(W_{\text {SSD }}-W_{\text {OD }}\right) /\left(W_{\text {OD }}\right) \times 100 \%$.

The absorption capacity of fine aggregate (LWA) RCA has an absorption capacity of $24 \%$ and $4.8 \%$, respectively. Being that the aggregates hold $24 \%$ and $4.8 \%$ moisture already, the amount of total water going into the mix was reduce by the percentage of absorption capacity. Aggregates were then pre-weighed a day before mixing to soak in water overnight to ensure reservoirs were filled with water.

To reduce any free surface water of aggregate, the materials were drained an hour before mixing to minimize extra moisture being placed into mix. RCA and LWA were added first into the mixing drum first and then water to spin. Cement was added to bond the ingredients. While the drum is spinning, the super plasticizer was added to strengthen bond and add workability to the ingredients. Once the mix came to a consistent workability, the set accelerator was the added to overpower the super plasticizer to force the concrete to set. When the method of IC is used specifically with LWA the concrete mixture has improved workability. (Figure 1).

The tests were carried out on ELE Internation Accu-Tek 350 Digital Series Compression Tester to test compressive strength and performance of the casted cylinder under a load at a pace rate of $439.79 \mathrm{lbf} / \mathrm{sec}$. After a series of test, the Accu-Tek Touch 350 will yield key readings in regards to the strength of the concrete mix. These readings will verify if whether or not the high-early strength can be achieved after 4 hours from the previous or long term 28-day strength. (Figure 2) 


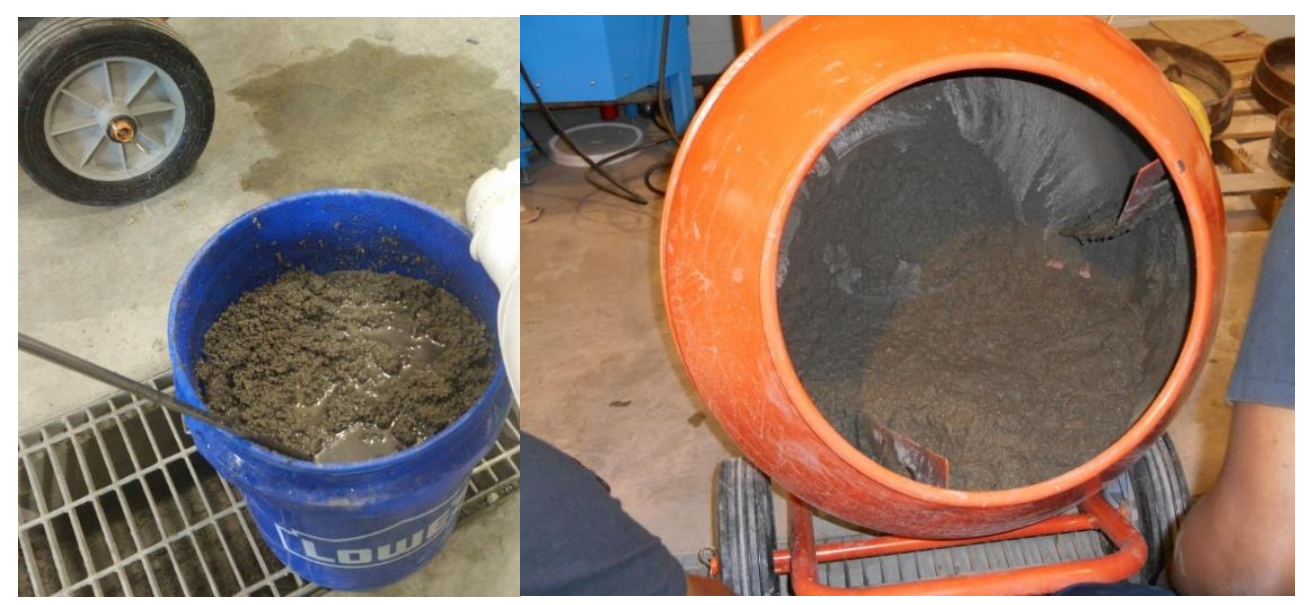

Figure 1. 24-hour soaked LWA for concrete mix
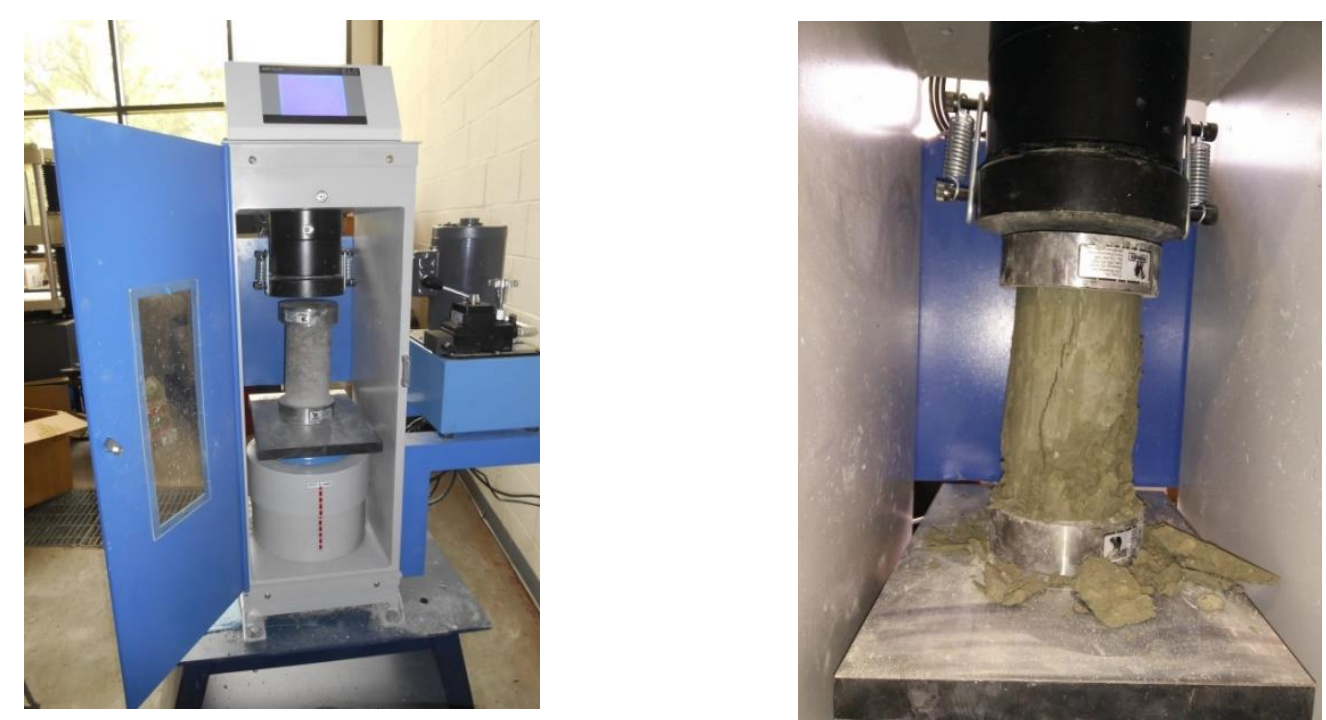

Figure 2. Compression Tester and 4-hour Compression Test

Based on the LA DOTD mixtures for rapid repaid as shown in Table 1, a variety of different alternatives were tried as shown in Table 2 to reduce the amount of water in the mix that contributes to a watery mix and wet cylinders after they are demolded. With mix 1 fully soaked LWA went into the mix without sand. The mix was not workable so $2 \mathrm{oz}$. of super plasticizer was added to compensate for that. Mix 2 the approach was to eliminate excess surface water on the aggregate in mix. Half of the total amount of LWA was only pre-soaked, half pre-soaked and half not pre-soaked LWA. Due to high moisture in mix 3 half of the amount of LWA was added to the mix and pre-soaked along with pre-soaked RCA. To keep the proportions true, half the total amount of fine aggregate was sand. For the last mix which resulted in the highest 4-hour strength test, no LWA was used. However, 2 additional oz super plasticizer was added not just for workability of the mix but for strength as well. Pre-soaked RCA and sand created a workable concrete mix that needed that resulted in a slightly higher strength.

Being that the presence of extra water in concrete mixing, it was necessary to consider other a SCM. The presence of extra water was due to the fact the pre-wet aggregates would hold excessive surface water. Although there are many controllable variables in mixing concrete, how well each piece of aggregate can still retain moisture on the surface is not one of them. Therefore, introducing silica fume, a by-product from the electric arc furnace used in the production of silicon metal or ferrosilicon alloys. It is commonly 
used as a partial substitute for Portland cement uses clinker through the use of less than total cementitious content while improving the durability to enhance a longer life for concrete pavement. It is an excellent way to reduce the cement productions carbon footprint. Manufacturing Portland cement is energy intensive that requires heating large quantities of grounded aggregates and other mineral extremely high temperatures. For this study we will look for it to absorb surface water on aggregates and to improve the concretes performance. Table 2 shows the mixing ingredients and their source or vendor.

Table 1. LA DOTD mixtures and materials used for trial mixes.

\begin{tabular}{|l|c|l|}
\hline \multicolumn{1}{|c|}{ MIX } & LADOTD $\left(27 \mathrm{ft}^{3}\right)$ & \multicolumn{1}{|c|}{ Source/Vendor } \\
\hline Cement Type III & 940 & Continental cement company \\
\hline RCA lbs. & 1663 & Red stick crushed concrete \\
\hline LWA lbs. & 0 & Oldcastle Inc. \\
\hline Water oz. & 25 gals & - \\
\hline Sand lbs. & 1352 & Bear Industries \\
\hline Accelerator oz. & 660 & MASTER BUILDER SOLUTIONS-BASF \\
\hline Super Plasticizer oz. & 84.6 & MASTER BUILDER SOLUTIONS-BASF \\
\hline
\end{tabular}

Table 2. Concrete mix design using Type III.

\begin{tabular}{|c|c|c|c|c|}
\hline & Mix 1 & Mix 2 & Mix 3 & Mix 4 \\
\hline Cement Type & Type III & Type III & Type III & Type III \\
\hline Cement (lbs) & 17.4 & 17.4 & 17.4 & 17.4 \\
\hline RCA (lbs) & 30.8 & wet 30.8 & wet 30.8 & Wet 30.8 \\
\hline LWA (lbs) & Wet 25.03 & Half wet 25.03 & Wet 12.5 & 0 \\
\hline Sand (lbs) & 0 & 0 & 12.5 & 59.26 \\
\hline Water (oz) & 61 & 42.25 & 59.26 & 12.22 \\
\hline Set Accelerator & 12.22 & 12.22 & 12.22 & 4 \\
\hline Super Plasticizer & 4 & 6 & 2 & \\
\hline
\end{tabular}

Concrete mixes that resulted in 4-hour strength but not the target goal of 4000 psi are listed in Figure 3. As this project moves forward using Type III cement, exploring different mix proportion of the current design are expected to yield us a higher recording results for 4-hour strength. After observation, mix concrete cylinders contained too much moisture, this apparent in how dark in color and wet the concrete cylinders are after demolding. That could be attributed to access surface water from aggregates and or too much water as an ingredient. The water content will be reduced by the absorption capacity as stated before. 


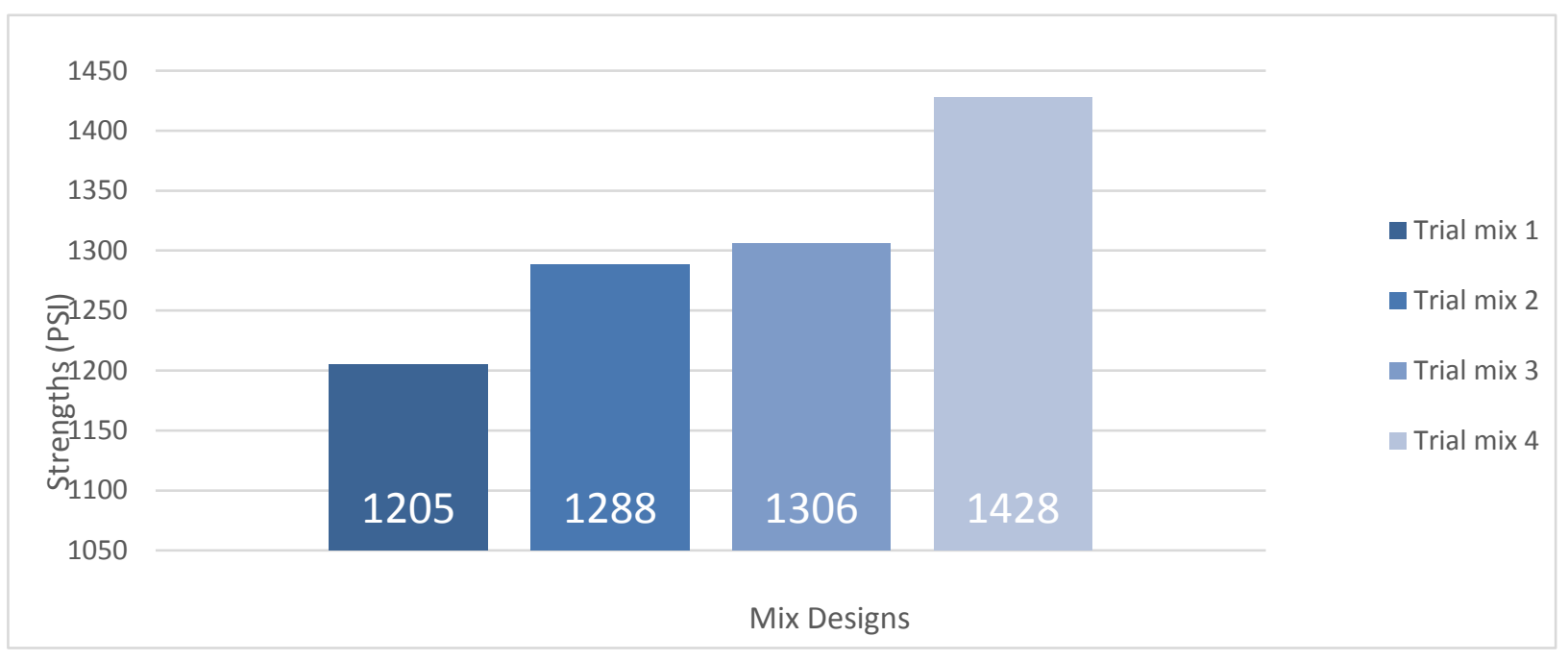

FIGURE 3. 4-HOUR STRENGTHS RECORDED

\section{EXPERIMENT 2 CONTINUED WITH SILICA FUMES}

Using silica fume has dramatically improved the performance of concrete under compression test. The silica fumes were replaced by total mass of cementious materials in three mixes between 6-10\% as shown in Table 3. Compression test were done at 4 and 8 hours to show the feasibility to use the concrete in paid pavement repair as shown in Figure 4. All the mixes tried did not make 4,000 psi in 4-hour, however, the test results show that silica fume helps to improve the concrete strength drastically. Figure 5 shows the strength development of the mixes for the 28 days.

\section{Table 3. Concrete mix design using silica fumes}

\begin{tabular}{|c|c|c|c|c|}
\hline MIX & $\begin{array}{c}\text { LA DOTD } \\
\left(27 \mathrm{ft}^{3}\right)\end{array}$ & Mix 1 & Mix 2 & Mix 3 \\
\cline { 3 - 5 } & & $6 \%$ Silica Fume & $8 \%$ Silica Fume & $10 \%$ Silica Fume \\
\hline Cement Type & Type I, II & Type III & Type III & Type III \\
\hline Cement lbs. & 940 & 16.36 & 16.008 & 15.66 \\
\hline LWA lbs. & 0 & wet 12 & wet 12 & wet 12 \\
\hline Water oz. & 25 gal & 42 & 42 & 42 \\
\hline Sand lbs. & 1352 & 12 & 12 & 12 \\
\hline Accelerator oz. & 660 & 12.22 & 12.22 & 2 \\
\hline Super Plasticizer oz. & 84.6 & 2 & 2 & 1.74 \\
\hline Silica Fumes lbs. & N/A & 1.04 & 1.39 & \\
\hline
\end{tabular}




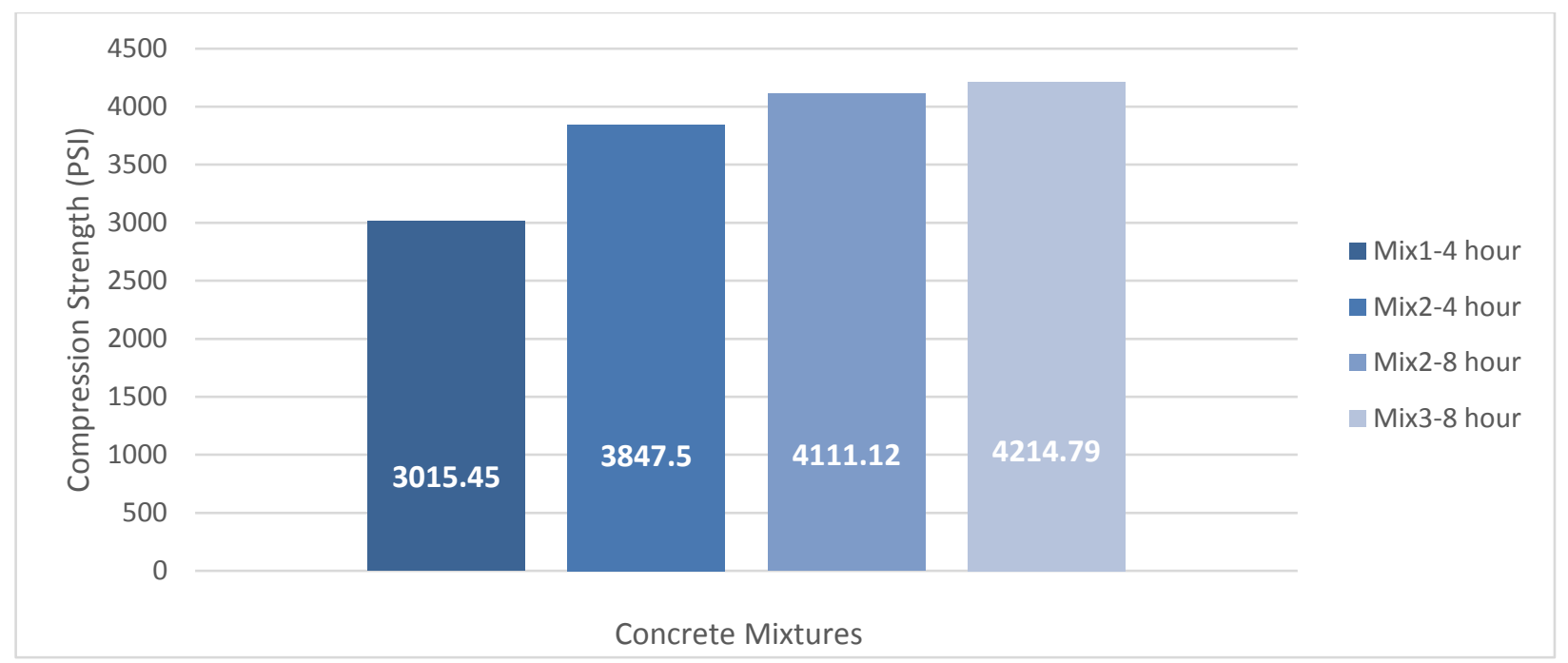

Figure 4. Graph of 4 and 8-hour compression strength using 6\%, 8\%, and $10 \%$ Silica Fumes respectively.

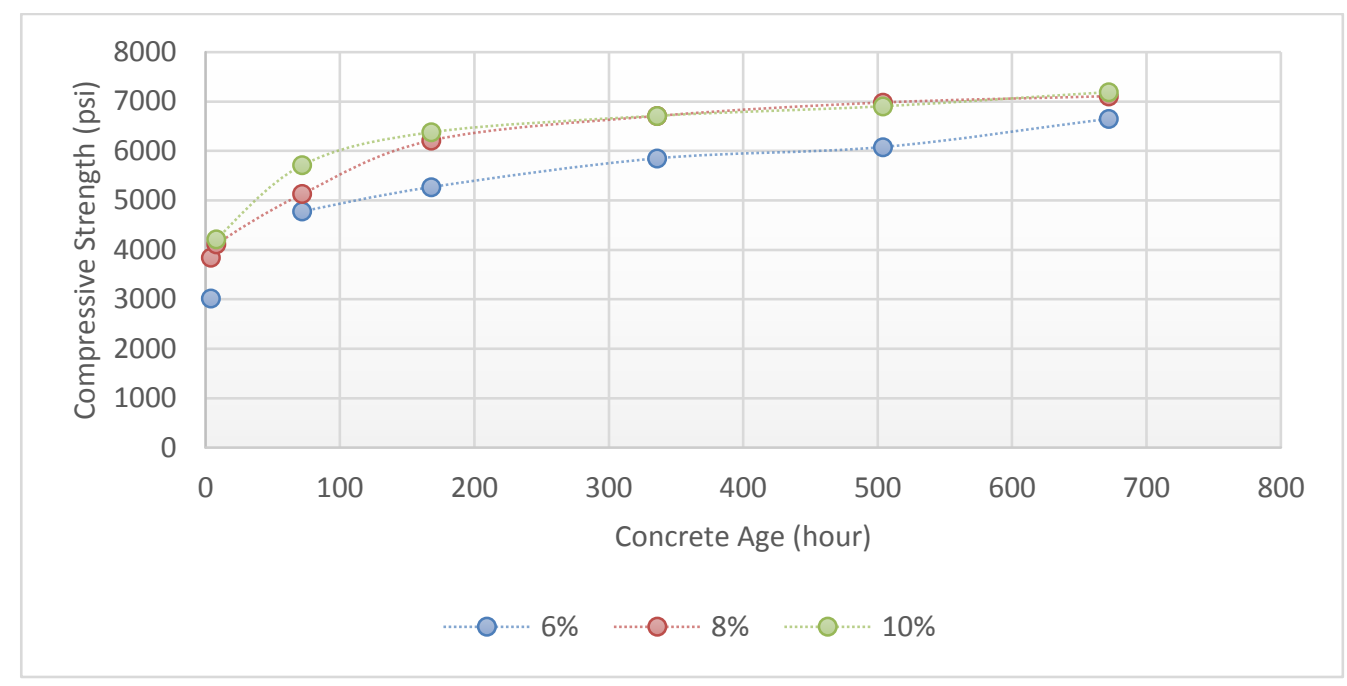

Figure 5. 28-day strength gains with addition of Silica Fumes

\section{CONCLUSION}

The mixes used in the study with RCA, internal curing, and silica fume did not make the target strength $(4,000 \mathrm{psi})$ in 4-hour to be used in rapid pavement repair. This is considered to the excessive moisture in the aggregates while adapting internal curing in the concrete cylinder. However, type III cement is a more suitable cementitious material for rapid road repair as it thinner and finer which preferable for greater heat hydration producing early strength concrete.

Silica fumes are necessary as surface water of the pre-soaked aggregate increase the moisture necessary to achieve high early strength concrete. Silica fume might help to absorb the surface water while also adding strength. Further research will prove this, as we continue to work towards different variations of ingredients in accordance to guideline specifications to improve the development of rapid PCC pavement repair materials. 


\section{REFERENCES}

ACI. "What is Internal Curing?" American Concrete Institute, 2 page.

ACI (308-213) R-13 Report on internally Cured Concrete Using Pre-Wetted Absorptive.

ACI $325.9 \mathrm{R}$

Bentur, A., Igarashi, S., \& Kovler, K. Prevention of autogenous shrinkage in high strength concrete by internal curing using wet lightweight aggregates, Accepted for publication, Cement and Concrete Research.

Bentz, D. P., \& Snyder, K. A. (1999). Protected paste volume in concrete. Extension to internal curing using saturated lightweight fine aggregate. Cement and Concrete Research 29: pp. 1863-1867.

Delatte, N.; Mack, E.; and Cleary, J., 2007, "Evaluation of High Absorptive Materials to Improve Internal Curing of Low Permeability Concrete," State Job No. 134227, Federal Contract Number 20809, Ohio Department of Transportation.

Dhir, K. R., Limbbachiya, M. C., \& Leelawat, T. (1999). Suitability of recycled concrete aggregate for use in BS 5328 Designated mixes, Proceedings of ICE: Structures \& Buildings 134. pp. 257-274.

Hansen, T. C. (1992). Recycling of demolished concrete and masonry, RILEM Report No.6, (E\&FN Spon, London).

Henkensiefken, R.; Briatka, p.; Bentz, D. P.; Nantung, T.; and Weiss, J., 2010, "Plastic Shrinkage Cracking in Internally Cured Mixtures, ” Concrete International, V.32, No. 2, Feb., pp. 49-54.

Kikuchi, K. Y. (1993). The total evaluation of recycled aggregate and recycled concrete, Proceedings of 3rd Int. RILEM Symp. Demolition and Reuse of Concrete \& Masonry, Odense, Denmark (E \& FN son, London). pp. 367-377.

Lauritzen, E. K. (1998). The global challenge of recycled concrete, Sustainable Construction: Use of Recycled Concrete Aggregate, Proceedings of an International Symposium, London. pp. 505-519.

Limbachiya, M. C. (1998). RCA Concrete: A study of properties in the fresh state, strength development and durability, Sustainable Construction: Use of Recycled Concrete Aggregate, Proceedings of an International Symposium, London. pp. 227-238.

Lura, P., van Breugel, K., \& de Vries, H. (2000). Moisture exchange as a basic phenomenon to understand volume changes of lightweight aggregate concrete at early age, Proceedings of international RILEM Workshop on Shrinkage of Concrete.

Rao, C., and Darter, M.I., 2013, "Evaluation of Internally Cured Concrete for Paving Applications," Applied Research Associates, Inc., Champaign, IL, 108 pp.

Rvindrajah, S. R. (1988). Strength Evaluation of Recycled-Aggregate Concrete by In-situ tests Material Structure 21. pp. 289-295.

Speare, R. S. (1994). Recycling of Structural Materials, The Structural Engineer 73 (13). pp. 220-222.

Taylor, P. C., S. H. Kosmatka, G. F. Voigt, D. Harrington, and J. Grove. 2007. Integrated Materials and Construction Practices for Concrete Pavements: A State-of-the-Practice Manual. FHWA-HIF-07004. National Concrete Pavement Technology Center, Iowa State University, Ames, IA.

Van Dam, T. J., K. R. Peterson, L. L. Sutter, A. Panguluri, and J. Sytsma, N. Buch, R. Kowli, and P. Desaraju. 2005. Guidelines for Early-Opening-to-Traffic Portland Cement Concrete for Pavement Rehabilitation. NCHRP Report 540. National Cooperative Highway Research Program, Transportation Research Board, Washington DC. <http://onlinepubs.trb.org/onlinepubs/nchrp/nchrp_rpt_540.pdf>.

Whiting, D. 1981. Rapid Determination of the Chloride Permeability of Concrete. FHWA/RD-81/119. Federal Highway Administration, Washington, DC.

Zhutovsky, S., Kovler, K., \& Bentur, A. (2001). Efficiency of lightweight aggregates for internal curing of high strength concrete to eliminate autogenous shrinkage. pp. 97-98. 